\title{
PREVALENCE OF TEMPOROMANDIBULAR DISORDERS AMONG JUNIOR HIGH SCHOOL STUDENTS WHO PLAY WIND INSTRUMENTS
}

\author{
ERIKO YASUDA, KOSUKE HONDA, YOKO HASEGAWA, EIKO MATSUMURA, MASANORI FUJIWARA, \\ MAKOTO HASEGAWA, and HIROMITSU KISHIMOTO
}

Hyogo College of Medicine, Hyogo, Japan

Department of Dentistry and Oral Surgery

\begin{abstract}
Objectives: This study investigated whether playing wind instruments has adverse effects on musculoskeletal functions among junior high school students who play in music clubs. Material and Methods: The study included 210 junior high school students ( 35 boys, 175 girls) belonging to 1 of 4 different school clubs that practiced playing wind instruments more than 6 days/week. The mean age of the participants was 14 years. The study was performed using a questionnaire survey and an electromyographic examination of jaw and cervical muscle activities during playing wind instruments. Results: The prevalence of temporomandibular disorders (TMD) among the children playing woodwind (WW) or brass wind (BW) instruments was higher than in those playing non-wind (NW) instruments. Long duration of playing WW with a reed mouthpiece or BW with a small mouthpiece was suggested to affect the incidence of TMD, which was more marked in girls than in boys, irrespective of height or weight. Muscle activity in the masseter muscle during playing an instrument was significantly higher in the BW with a small mouthpiece group than in the NW group $(\mathrm{p}<0.05)$. In cervical muscles, muscle activity of both the sternocleidomastoid and trapezius muscles was higher during playing BW than in the case of other instruments, and activity in the sternocleidomastoid muscle was significantly higher in the BW with a small mouthpiece group than in the case of other instrument groups $(\mathrm{p}<0.05)$. Conclusions: Playing wind instruments may have adverse effects on musculoskeletal functions among junior high school students playing in music clubs as compared with playing NW instruments. The prevalence of TMD among the students playing wind instruments was higher than in those playing other instruments. Long duration of playing those instruments affects musculoskeletal function, and this effect is more marked in girls than in boys, irrespective of height or weight.
\end{abstract}

Key words:

Adolescence, Temporomandibular disorders, Temporomandibular joint, Playing-related musculoskeletal disorder, Wind instruments, Maximal voluntary contraction

\section{INTRODUCTION}

Temporomandibular disorders (TMD) are generally known to be induced by various combinations of onset and contributing factors. Traumatic stress on the temporomandibular joints (TMJs), over-stretching of the jaw and a sudden bite change can be listed as some examples of such onset factors. Whereas, examples of contributing factors include clenching and grinding the teeth, which are also considered as predisposing factors for TMD.

Playing wind musical instruments has recently been reported to be associated with various musculoskeletal disorders [1-3]. Much attention has been paid to

This work was partly supported by Grants-in-Aid for Researchers, Hyogo College of Medicine, 2014. Grant manager: Kenji Nakanishi, M.D., Ph.D., President. Received: December 1, 2014. Accepted: March 4, 2015.

Corresponding author: K. Honda, Hyogo College of Medicine, Department of Dentistry and Oral Surgery, 1-1 Mukogawa-cho, Nishinomiya, Hyogo 663-8501, Japan (e-mail: ko-honda@hyo-med.ac.jp). 
playing-related TMD among professional wind instrument musicians $[4,5]$. There is no doubt that professional musicians often participate in long music sessions where they play their instruments. However, supporting evidence is lacking regarding whether the rate of playing-related TMD in musicians has risen because of playing their instruments for long periods. The prevalence of TMD in the adolescent population is high, and the influence of TMD on headache and other general pubertal symptoms have been researched [6-10]. Therefore, a survey among relatively inexperienced wind instrument players, like junior high school students, may be an appropriate way to determine whether wind instrument performance is a causal factor for TMD.

In Japan, club activities for junior high school students have recently been intensified. Very little information has been gathered on how playing wind instruments can adversely affect temporomandibular joints (TMJs) and masticatory muscles of juveniles. This study was undertaken to clarify whether playing wind instruments as part of club activities can adversely affect musculoskeletal functions in junior high school students, and whether the development of TMD varies by the type of an instrument, practice times, experience in playing the instrument, height, weight, and body mass index (BMI) of the player. Furthermore, jaw and cervical muscle activities during playing music were compared among instruments to estimate which types of instruments are more likely to be associated with TMD.

\section{MATERIAL AND METHODS}

The participants of the study were 210 junior high school students (35 boys, 175 girls) belonging to 1 of 4 different school clubs that practiced playing wind instruments $>6$ days/week. The mean age of the study participants was 14 years (Table 1). All the subjects and their parents were informed of the nature and possible risks of this study, and that they were free to withdraw from it at any time. Then, they were asked, in the presence of
Table 1. Study group characteristics

\begin{tabular}{lc}
\hline \multicolumn{1}{c}{ Variable } & $\begin{array}{c}\text { Respondents } \\
(\mathrm{N}=210)\end{array}$ \\
\hline Sex $[\mathrm{n}]$ & 35 \\
boys & 175 \\
girls & $14.0 \pm 0.9$ \\
Age [years] $(\mathrm{M} \pm \mathrm{SD})$ & $156.0 \pm 7.0$ \\
Height $[\mathrm{cm}](\mathrm{M} \pm \mathrm{SD})$ & $45.0 \pm 8.0$ \\
Weight $[\mathrm{kg}](\mathrm{M} \pm \mathrm{SD})$ & $18.4 \pm 2.4$ \\
Body mass index $\left[\mathrm{kg} / \mathrm{m}^{2}\right](\mathrm{M} \pm \mathrm{SD})$ & $19.0 \pm 13.0$ \\
Experience in instrument playing [months] & \\
(M $\pm \mathrm{SD})$ & \\
Practice time $[\mathrm{h}](\mathrm{M} \pm \mathrm{SD})$ & $26.3 \pm 8.4$ \\
a week & $7.5 \pm 2.6$ \\
\hline
\end{tabular}

M - mean; SD - standard deviation.

a witness, to sign a consent form indicating their willingness to participate in the study. All the study protocols were approved by the ethics committee at Hyogo College of Medicine (No. 1570).

\section{Investigation of TMD prevalence using a questionnaire}

In order to assess whether playing a wind instrument acts as an onset and/or contributing factor for TMD, we used a questionnaire that was previously developed for TMD screening by Sugisaki et al. [11,12]. The questionnaire is composed of the following 4 items:

- range of maximum mouth opening,

- identification of joint pain on mouth opening,

- presence of jaw deviation on mouth opening,

- pain when chewing hard foods.

The following are the specific questions suggested in the questionnaire [11]:

1. If you open your mouth wide, can you fit 3 fingers held vertically in your mouth?

2. Do you experience pain in the face, jaw, temple, or in front of the ear when you open and close your mouth? 
3. Can you open your mouth without any deviation?

4. Do you experience pain in the face, jaw, temple, or in the front of the ear when you eat chewy foods such as beef jerky, dried cuttlefish, or octopus?

The subjects were asked to answer questions 1-4 on a 5-point numeric rating scale, where 1 stood for strongly agree, 2 - weakly agree, 3 - neither agree nor disagree, 4 - weakly disagree, and 5 - strongly disagree.

Sensitivity, specificity, and false-positive rates of 0.746 , 0.811 , and 0.189 , respectively, were reported [11]. The inclusion of an item on joint noise was found to reduce the validity of the screening as determined by the item response theory analysis [11]. The severity of the response to each item was given a score $1-5$, and scores for all items were totaled (max score: 20 ). Total score $\geq 8.5$ was considered as indicative of TMD in accordance with the previous report [11].

Based on the musical instrument they played, the subjects were classified into 3 groups: woodwind instrument (WW) players; brass wind instrument players (BW); or a control group with non-wind instrument (NW). Additionally, the WW and BW groups were divided into 2 subgroups as suggested by Grammatopoulos et al. [13], including instruments with or without a reed mouthpiece (wR and woR, respectively) in the WW group, and with a small mouthpiece (SM) or a large mouthpiece (LM) in the BW group.

The breakdown of each group was as follows: WW-wR group $-\mathrm{N}=79$; WW-woR group $-\mathrm{N}=23$; BW-SM group $-\mathrm{N}=42$; BW-LM group $-\mathrm{N}=40$; and $\mathrm{NW}$ group $-\mathrm{N}=26$. The prevalence of TMD in the WW-wR, WW-woR, BW-SM and BW-LM groups was compared to that in the NW control group. To clarify the influence of a student's background characteristics, such as age, sex, BMI, months of experience in playing the musical instrument and hours of practice on TMD prevalence, the correlation between each factor and the presence of TMD was examined.

\section{Examination of muscle activity in temporalis, masseter, sternocleidomastoid, and trapezius muscles during playing an instrument}

Forty-eight students (11 boys, 37 girls; mean age: 13.3 years) who provided an informed consent were selected at random from the group of 210 students involved in the questionnaire survey. Muscle activity during playing an instrument was assessed using electromyography (EMG). Wireless surface EMG (TELEMYO-G2; Noraxon, Scottsdale, AZ, USA) was used in the examination. Myogenic potential (MP) was measured in 4 muscles: masseter; temporalis; sternocleidomastoid; and trapezius. Surface electrodes (Blue Sensor, N-00-S; Ambu, Copenhagen, Denmark) were attached to the belly of each muscle bilaterally while keeping a $20-\mathrm{mm}$ inter-electrode distance to minimize interference between the instruments. The indifferent electrode was placed on the clavicle.

First, the MP of each muscle on maximum contraction was measured for $5 \mathrm{~s}$ before playing an instrument; this was regarded as the maximal voluntary contraction (MVC) of each subject. The measurement of MP during playing an instrument for $50 \mathrm{~s}$ was then carried out under the same conditions with 1 of the following 5 types of instruments: WW-wR, WW-woR, BW-SM, BW-LM and NW. Each instrument was used to play the song "Edelweiss." The speed of performance was regulated to "moderato," at 112 beats/min with a metronome. The signals for MP were processed by a filter at a sampling frequency of $1500 \mathrm{~Hz}$ (range: $10-1000 \mathrm{~Hz}$ ), and the mean amplitude of each muscle was calculated by the use of the data analysis software applied for this type of electromyography (Myo Research XP; Noraxon). To obtain the percentage of MVC for each muscle (\%MVC), the MP on playing each instrument was divided by the MVC on maximum clenching.

\section{Statistical analysis}

The Chi-square test $\left(\mathrm{Chi}^{2}\right)$ was used to determine differences in the prevalence of TMD between the WW and NW groups, 
and between each WW group and BW group (WW-wR, WW-woR, BW-SM, and BW-LM) and the NW group. To investigate associations between the subject characteristics (sex, age, months of playing experience, number of hours of practice each day, number of hours of practice each week and BMI) and the prevalence of TMD, multiple logistic regression analyses were performed. The Hosmer-Lemshow test was used to evaluate goodness of fit.

Numbers of hours of practice per day and per week for each instrument were compared between the TMD and non-TMD groups using the Mann-Whitney $U$ test and differences with $p<0.05$ were considered significant.

Percentage MVC values for each muscle among the WW-wR, WW-woR, BW-SM, BW-LM and NW groups were compared using the Kruskal-Wallis analysis of variance. Pairwise comparisons between each group were made using the Mann-Whitney $U$ test, with values of $p<0.05$ considered significant.

Statistical analyses ware performed using SPSS version 20.0 software (SPSS, Chicago, IL, USA).

\section{RESULTS}

\section{Investigation of TMD prevalence using the questionnaire}

The overall TMD prevalence in the 210 students playing wind instruments as part of club activities was $89 \%$.
The rate of TMD in the students playing wind instruments (WW and BW) was 34.8\%, significantly higher than for those playing NW ( $p=0.001)$. As an index representing the relative risk of TMD and predicting development, the odds ratio (OR) of the NW group was calculated and compared with those of the WW and BW groups. Odds ratio for the WW-wR group was 23.17 (95\% confidence interval (CI): 2.99-179.43, $\mathrm{p}<0.001$ ), and ORs for the WW-woR and BW-SM groups were significantly higher than that for the NW group (Table 2).

Among characteristics of the students, OR was significantly higher for the female students than that for the male students (95\% CI: $1.01-8.34, \mathrm{p}=0.003)$. The data also suggested that increasing the hours of practice per day led to a higher risk of TMD (95\% CI: 1.07-1.4, $\mathrm{p}=0.004$ ) (Table 3 ). The incidence of TMD was significantly higher $(p=0.016)$ with longer practice hours in the BW-SM group (Figure 1a-d).

\section{Examination of temporalis, masseter,} sternocleidomastoid, and trapezius muscle activities while playing each instrument

The percentage of MVC (\% MCV) of each muscle on playing an instrument is presented as the median \pm standard error $(\mathrm{Me} \pm \mathrm{SE})$. The $\% \mathrm{MVC}$ of the masseter muscle

Table 2. Comparison of odds ratios among the musical instrument groups to identify the risks and predictors of temporomandibular disorders (TMD)

\begin{tabular}{lcccr}
\hline \multicolumn{1}{r}{ Instrument } & $\begin{array}{c}\text { Prevalence } \\
{[\%]}\end{array}$ & OR & $95 \% \mathrm{CI}$ & $\mathrm{p}^{*}$ \\
\hline NW (control) $(\mathrm{N}=26)$ & 3.8 & reference & - & - \\
WW and BW $(\mathrm{N}=184)$ & 34.8 & 13.33 & $1.77-100.68$ & 0.001 \\
WW-wR $(\mathrm{N}=79)$ & 48.1 & 23.17 & $2.99-179.43$ & $<0.001$ \\
WW-woR $(\mathrm{N}=23)$ & 34.8 & 13.33 & $1.52-117.38$ & 0.005 \\
BW-SM $(\mathrm{N}=42)$ & 31.0 & 11.21 & $1.39-91.80$ & 0.007 \\
BW-LM $(\mathrm{N}=40)$ & 12.5 & 3.57 & $0.39-32.48$ & 0.200 \\
\hline
\end{tabular}

NW - non-wind instrument; WW - woodwind instrument; BW - brass wind instrument; WW-wR - woodwind instrument with a reed mouthpiece; WW-woR - woodwind instrument without a reed mouthpiece; BW-SM - brass wind instrument with a small mouthpiece; BW-LM - brass wind instrument with a large mouthpiece.

OR - odds ratio; $\mathrm{CI}$ - confidence interval.

* Significant difference $(\mathrm{p}<0.05), \mathrm{Chi}^{2}$ test. 
Table 3. Comparison of odds ratios among the subjects to identify the risks and predictors of temporomandibular disorders (TMD)

\begin{tabular}{lccc}
\hline \multicolumn{1}{c}{ Variable } & OR & $95 \% \mathrm{CI}$ & $\mathrm{p}^{*}$ \\
\hline Sex (male) & 0.01 & $1.01-8.34$ & 0.003 \\
Body mass index $\left[\mathrm{kg} / \mathrm{m}^{2}\right]$ & 1.07 & $0.94-1.22$ & 0.300 \\
Experience of playing instruments [months] & 0.99 & $0.97-1.02$ & 0.600 \\
Practice time [h/day] & 1.22 & $1.07-1.40$ & 0.004 \\
\hline
\end{tabular}

* Significant difference $(\mathrm{p}<0.05)$, multiple logistic regression analysis.

Other abbreviations as in Table 2.
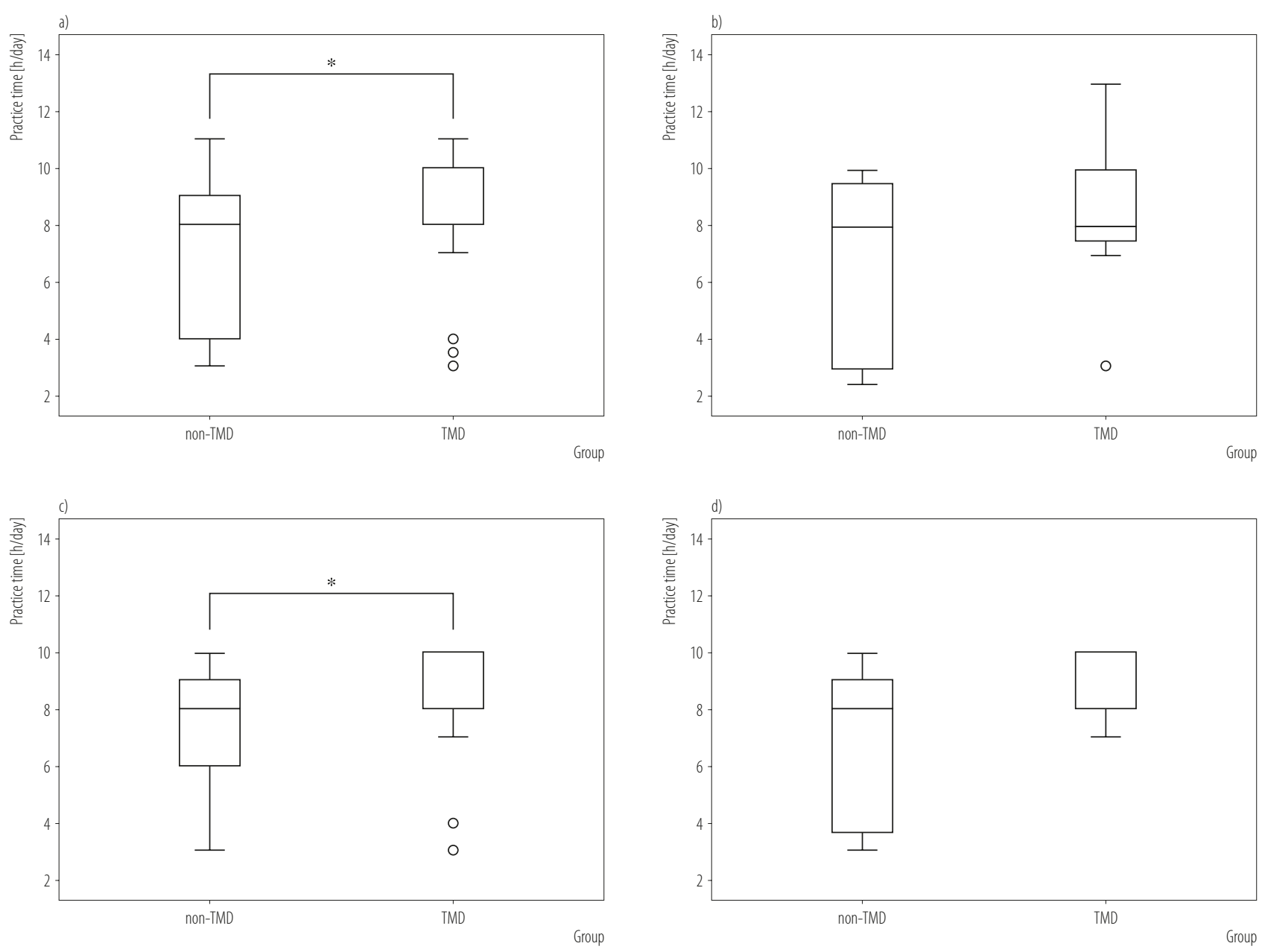

*Significant difference $(\mathrm{p}<0.05)$, Mann-Whitney U test.

Fig. 1. Comparison of practice hours for each instrument between temporomandibular disorder (TMD) and non-TMD groups: a) woodwind instrument with a reed mouthpiece (WW-wR), b) woodwind instrument without a reed mouthpiece (WW-woR), c) brass wind instrument with a small mouthpiece (BW-SM), d) brass wind instrument with a large mouthpiece (BW-LM) 

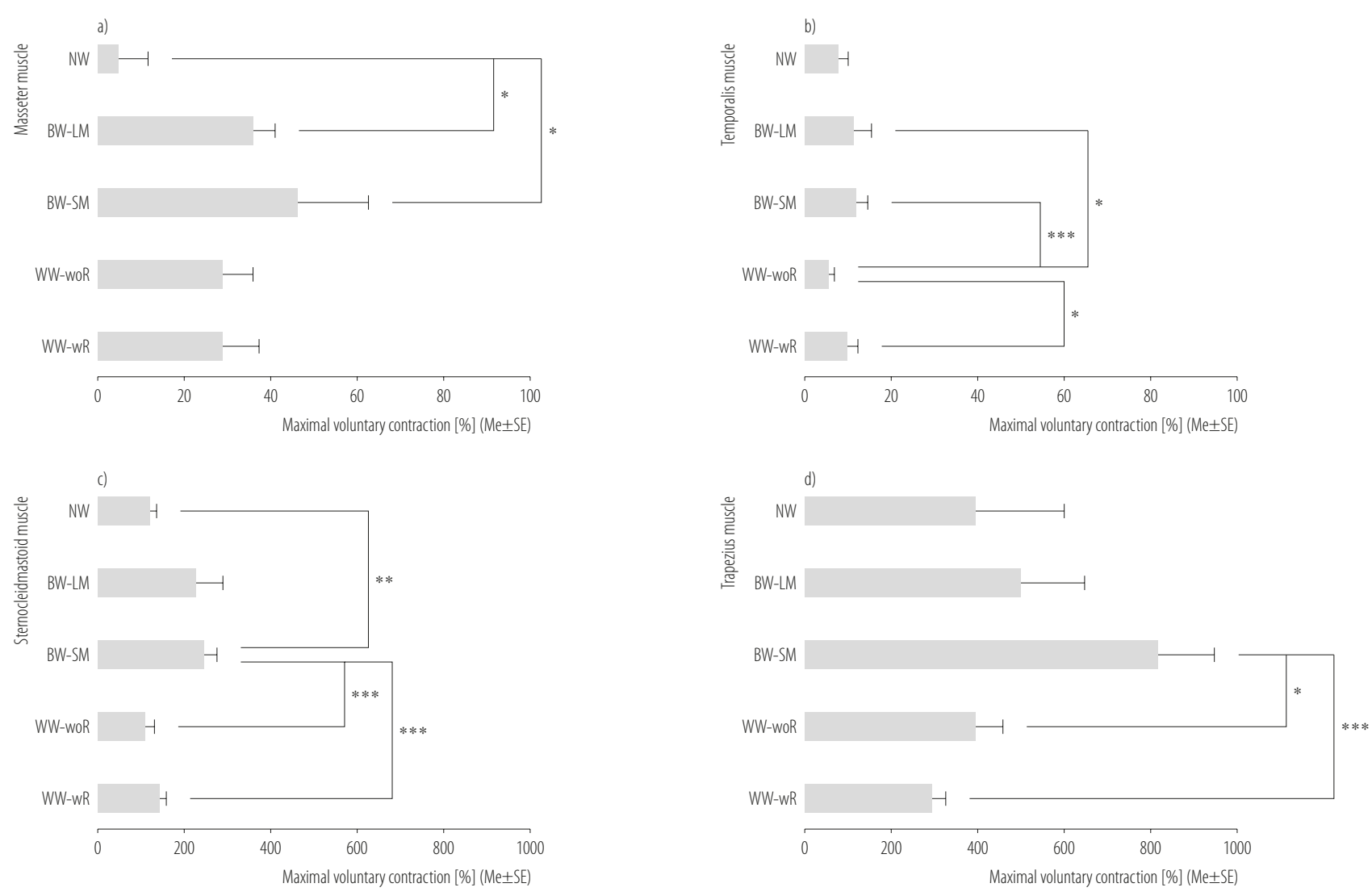

$\mathrm{Me}$ - median; SE - standard error.

${ }^{*} \mathrm{p}<0.05 ;{ }^{* *} \mathrm{p}<0.01 ;{ }^{* *} \mathrm{p}<0.005$ - significantly different, Kruskal-Wallis test and Mann-Whitney U test.

Fig. 2. Comparison of the mean percentage of maximal voluntary contraction (\% MVC) for each muscle among woodwind instruments with a reed mouthpiece (WW-wR), woodwind instruments without a reed mouthpiece (WW-woR), brass wind instruments with a small mouthpiece (BW-SM), brass wind instruments with a large mouthpiece (BW-LM), and control (NW) groups: a) masseter muscle, b) temporalis muscle, c) sternocleidomastoid muscle, d) trapezius muscle

was $46.1 \pm 16.5 \%$ in the BW-SM group, $35.9 \pm 5.1 \%$ in the BW-LM group and $4.3 \pm 7.2 \%$ in NW group, with significantly higher results in the BW-SM group $(p<0.05)$ than in the NW group. In the temporalis muscle, a significant difference $(\mathrm{p}<0.05)$ was found between the WW-wR and WW-woR groups. Namely, \%MVC in the WW-wR group $(9.4 \pm 2.7 \%)$ was higher than in the WW-woR group $(5.6 \pm 0.9 \%)$, and almost the same as in the BW-SM $(11.8 \pm 2.7 \%)$ and BW-LM $(11.6 \pm 3.7 \%)$ groups (Figure 2a).

In cervical muscles, the \% MVC of both the sternocleidomastoid and trapezius was higher during playing a BW than in the case of other instruments, and that of the sternocleidomastoid muscle was significantly higher in the BW-SM group $(\mathrm{p}<0.05)$ than in the other instrument groups except for the BW-LM group. The \%MVC of the trapezius muscle in the BW-SM group $(816.3 \pm 132 \%)$ was significantly higher $(\mathrm{p}<0.05)$ than in the WW-wR $(293.1 \pm 33.7 \%)$ and WW-woR (389.8 $\pm 67.7 \%)$ groups (Figure $2 b)$.

\section{DISCUSSION}

The effects of playing wind instruments on the musculoskeletal functions of junior high school students are interesting, but have attracted little attention to date. In our 
study, the prevalence of TMD in the junior high school students playing wind musical instruments, (both wood and brass instruments) was $34.8 \%$, and the prevalence was higher in girls than in boys. Moreover, comparison of the result of our study with other reports [7-9] on screening examinations for TMD in high school and junior high school students, proved that the assumption that playing wind instruments has some adverse effect on musculoskeletal condition is not new. The critical point is clarification which types of wind instruments aggravate musculoskeletal condition, and which factors are associated with the development of TMD among inexperienced adolescent wind instrument players.

We found that WW-wR, WW-woR, and BW-SM yielded higher rates of TMD prevalence compared with NW. The questionnaire showed that WW instruments, particularly those with a reed mouthpiece (WW-wR), were significantly correlated with the risk of TMD. However, in this study, the prevalence of TMD was higher with longer hours of practice in the BW-SM group than in the WW group. Thus, the development of musculoskeletal symptoms may not be associated with the increased hours of practice in the WW group. We must, therefore, pay careful attention to the actual conditions of club activities with wind instruments and the severity of TMD in students, because the onset of TMD was earlier in relation to less experience in playing such instruments.

An examination of the average electromyographic activity during playing each wind instrument showed that the \% MVC of the masseter muscle was significantly higher during playing BW-SM instruments than when playing NW instruments. The \%MVC of the sternocleidomastoid and trapezius muscles during playing BW-SM instruments was significantly higher than in the WW-wR and WW-woR groups. These results are noteworthy. Playing a BW instrument causes a substantial strain on the masseter muscles bilaterally when players contact the maxillary and mandibular incisors with the mouthpiece with horizontal force and blow air into the small orifice of the instrument.

Grammatopoulos et al. [13] have reported the possibility that playing a BW instrument can cause malocclusion and lingual crossbite, but the effects on the masseter muscle have not been mentioned. Masseter muscle activity may also increase markedly when inexperienced players blow air strongly into a small mouthpiece of a BW-SM, such as a trumpet or French horn, to play loud notes. However, Gotouda et al. [14] have investigated EMG activity of jaw muscles in wind instruments playing among players who were 15-27 years of age, and have reported no significant difference in the activities of masticatory muscles between BW and WW. Further study is warranted to clarify these issues.

Trapezius muscle activity was higher when playing BW-SM instruments, potentially associated with the weight of an instrument or the posture of the player. For example, French horn players frequently suffer from cervical pain, as they need to hold this heavy BW-SM instrument in their arms when playing. In contrast, when playing the tuba, a BW-LM instrument heavier than the French horn, the instrument is not held in the arms, but placed on the knees, which may explain the lower trapezius muscle activity level observed in the case of this instrument.

Kaufman-Cohen et al. [1] have made a similar observation regarding myalgia in professional musical instrumentalists. They have reported that the odds ratio for cervical pain in stringed instrumentalists was 2.5-times higher than that in wind instrumentalists. In the present study, associations between cervical pain and a player's posture or an instrument weight, which are evident in professionals, were also found in the inexperienced young players.

\section{CONCLUSIONS}

This study was carried out based on a questionnaire survey and examination of jaw and cervical muscle activities to clarify whether playing wind instruments is associated with adverse effects on musculoskeletal functions among 
junior high students playing in music clubs. The prevalence of TMD among the students playing WW and BW instruments was higher than in those playing NW instruments; long duration of playing WW-wR and BW-SM instruments seemed to affect the incidence of TMD, which was more marked in girls than in boys, irrespective of height or weight.

\section{ACKNOWLEDGMENTS}

We are grateful to Prof. M. Shima (Department of Public Health, Hyogo College of Medicine) for his helpful advice regarding this study.

\section{REFERENCES}

1. Kaufman-Cohen Y, Ratzon NZ. Correlation between risk factors and musculoskeletal disorders among classical musicians. Occup Med (Lond). 2011;61(2):90-5, http://dx.doi. org/10.1093/occmed/kqq196.

2. Engquist K, Orback P, Jakobsson K. Musculoskeletal pain and impact on performance in orchestra musicians and actors. Med Probl Perform Art. 2004;19(2):55-61.

3. Zaza C, Farewell VT. Musicians' playing-related musculoskeletal disorders: An examination of risk factors. Am J Ind Med. 1997;32(3):292-300, http://dx.doi. org/10.1002/(SICI)1097-0274(199709)32:3<292::AIDAJIM16>3.0.CO;2-Q.

4. Leaver R, Harris EC, Palmer KT. Musculoskeletal pain in elite professional musicians from British symphony orchestras. Occup Med (Lond). 2011;61(8):549-55, http://dx.doi. org/10.1093/occmed/kqr129.

5. Caldron PH, Calabrese LH, Clough JD, Lederman RJ, Williams G, Leatherman J. A survey of musculoskeletal problems encountered in high-level musicians. Med Probl Perform Art. 1986;1(4):136-9.

6. Liljeström M-R, Bell YL, Anttila P, Aromaa M, Jämsä T, Metsähonkala L, et al. Headache children with temporomandibular disorders have several types of pain and other symptoms. Cephalalgia. 2005;25(11):1054-60, http://dx.doi. org/10.1111/j.1468-2982.2005.00957.x.

7. Winocur E, Littnerusb D, Adamusb I, Gavish A. Oral habits and their association with signs and symptoms of temporomandibular disorders in adolescents: A gender comparison. Oral Surg Oral Med Oral Pathol Oral Radiol Endod. 2006;102(4):482-7, http://dx.doi.org/10.1016/j.tripl eo.2005.11.007.

8. Winocur E, Gavish A, Finkelshetein T, Halachmi M, Gazit E. Oral habits among adolescent girls and their association with symptoms of temporomandibular disorders. J Oral Rehabil. 2001;28(7):624-9, http://dx.doi.org/10.1046/j.13652842.2001.00708.x.

9. List T, Wahlund K, Wenneberg B, Dworkin SF. TMD in children and adolescents: Prevalence of pain, gender differences, and perceived treatment need. J Orofac Pain. 1999; 13(1):9-20.

10. Lederman RJ. Neuromuscular and musculoskeletal problems in instrumental musicians. Muscle Nerve. 2003;27(5): 549-61, http://dx.doi.org/10.1002/mus.10380.

11. Sugisaki M, Kuruma E, Kino K, Tsukahara H, Shimada A, Tamai K, et al. [Selection of question items for screening patients with temporomandibular disorders and estimation of their validity]. J Jpn Soc TMJ. 2007;19(2):177-84. Japanese.

12. Nishiyama A, Kino K, Sugisaki M, Tsukagoshi K. A survey of influence of work environment on temporomandibular disorders-related symptoms in Japan. Head Face Med. 2012;8:24, http://dx.doi.org/10.1186/1746-160X-8-24.

13. Grammatopoulos E, White AP, Dhopatkar A. Effects of playing a wind instrument on the occlusion. Am J Orthod Dentofacial Orthop. 2012;141(2):138-45, http://dx.doi. org/10.1016/j.ajodo.2011.06.044.

14. Gotouda A, Yamaguchi T, Okada K, Matsuki T, Gotouda S, Inoue $\mathrm{N}$. Influence of playing wind instruments on activity of masticatory muscles. J Oral Rehabil. 2007;34(9):645-51, http://dx.doi.org/10.1111/j.1365-2842.2007.01765.x.

This work is available in Open Access model and licensed under a Creative Commons Attribution-NonCommercial 3.0 Poland License - http://creativecommons.org/ licenses/by-nc/3.0/pl/deed.en. 